\title{
Gülüşan Göcen, Psikoloji, Mitoloji ve Din,
} (İstanbul: Kaknüs Yayınları, 2018) 376 s.

Mitoloji, psikoloji ve din üçgeninin kesişim kümesine odaklanarak insan yapısını inceleyen Gülüşan Göcen'in bu eseri, modern psikolojinin mitosa nasıl yaklaştığı ve din psikolojisinin sahip olduğu yöntem ve yaklaşımlar çerçevesinde mitosların nasıl ele alınabileceği sorularına yanıt aramaktadır. Oldukça yoğun ve uzun soluklu bir araştırmanın ürünü olduğu kolaylıkla farkedilen eserde Göcen; ilk bölümde kitap süresince peşinde olacağı soruları, konu ve sınırlılıkları izah etmekte, ikinci bölümde ise mitosun ne'liği, işlevi, yapısı ve özellikleri gibi başlıklardaki tartışmalara değinerek "mit ve din", "mit ve psikoloji" ilişkilerini bütün boyutlarıyla gözler önüne sermektedir. Üçüncü bölümü modern psikologların mitosları okuma biçimlerine ayıran yazar, son bölümde ise mitosu daha dar bir perspektiften - din psikolojisinin sınırları dahilinde - ele almaktadir.

Varoluşsal kaygılar ve sorular arasında sıkışan insanın kendisine, evrene ve hayata dair ilk yapısal açıklamaları olarak kabul edilen mitlere ilişkin birbirinden farklı tanımlara ve bu tanımlar etrafında yapılan tartışmalara yer veren Göcen, her ne kadar kitap süresince mitosları din ve psikoloji perspektifleri üzerinden bir değerlendirmeye tabi tutacağını ifade etse de, mitosların anlaşılması için etnoloji, arkeoloji, antropoloji, dilbilim gibi pek çok farklı disiplinin mitler hakkındaki yorumlarınını da yer yer çalışmasına dahil etmiştir. Öncelikle mit ve din arasındaki ilişkinin kaçınılmazlığına değinen yazar, hem dinin hem de mitlerin insanın varoluşsal sorularını cevaplandırma ve hayatı anlamlandırma gibi temel işlevlere sahip olduğunun altını çizer. Mitosların toplumsal hayatı düzenlemeye yönelik etkileri göz önüne alındığında yazara göre söz konusu ilişkinin kaçınılmazlığı da apaçık ortaya çıkmaktadır (s. 84). 
Mitlerin mi dinin kökeni, yoksa dinin mi mitlerin kökeni olduğu tartışması bir yana mitsiz bir anın bulunmadığına yönelik tezlerin baskınlığ insanlığın din ve mit sarkacında yaşadığı söylenebilir. Her iki olgunun ortak değeri olarak beliren "kutsalı anlama", aynı zamanda "insanı anlamak" olarak değerlendirilmiştir. Bu sebeple mitler yalnızca dinler tarihçilerinin değil antropoloji, sosyoloji, felsefe ve psikoloji sahalarındaki araştırmacıların da dikkatini çekmektedir. Oldukça geniş bir yelpazeye sahip mit araştırmaları neticesinde (i) mit ve dinin kökenini aynı kaynağa dayandıran; (ii) miti dini inançların bozulmuş bir hali olarak kabul eden; ve (iii) mit ve din arasında herhangi bir bağ kabul etmeyen üç ayrı görüşün varlığına ulaşılabilir. Mit ve dinin aynı kaynağa dayandığını savunan görüşün her iki olguyu aynılaştırma tehlikesi barındırdığına dikkat çeken Göcen'in benzerliklerle birlikte farklılıkların da gözetilmesi gerektiğine değinmesi ve böylece hem mitin hem de dinin özgünlüğünü muhafaza ederek aralarındaki ilişki biçimini anlamaya çalışması oldukça yerindedir. Çünkü mit ve din birbirinin yerine ikame edilen iki olgu değil, insanlığın dini tecrübesinin anlaşılması için kesinlikle bütüncül bir şekilde ve birlikte ele alınması gereken iki kavramdır. Dini metinlerin anlaşılması için söz konusu metinlerin teşekkül ettiği kontekste ait mitolojik anlatılarının bilinmesi oldukça önemlidir. Aynı şekilde mitolojik anlatıların anlaşılmasında ise dini metinlerin son derece önemli bir referans kaynağı olduğu doğrudur. Nitekim Mircea Eliade'ye göre mitler sürekli olarak bir ritüele bağlanmış ve dini bir davranışı doğrulayıcı ve açıklayıcı bir işlev üstlenmiştir (s. 86-90).

Miti, dini ve ikisi arasındaki ilişkiyi sadece kavramsal düzeyde ele almayan Göcen, bu ilişkiyi Hıristiyanlık ve İslam örnekleri üzerinden de değerlendirmektedir. Yazar, Hıristiyanlığın ortaya çıtığı dönemin mitolojik dilini, sembollerini ve hatta figürlerini kullanarak yeni mitler ürettiğine dikkat çeker. Dinler Tarihi Okulu'nun önemli temsilcilerinden Rudolf Bultmann'ın "mitolojiden arındırma" (demitolojizasyon) söylemi, Hıristiyanlık ve mitoloji arasındaki bağlantıları anlamak açısından oldukça önemldir. Mitik dilin yoğun sembolik yapısı Bultmann'a göre Hiristiyan hakikatin üstünü örtmekte ve bu sebeple modern insan tarafından anlaşılmasını zorlaştırmaktadır. Bultmann'ın kerigma adını verdiği hakikat, ancak 
örtük bir şekilde yer aldığı mitoslardan arındırılmak suretiyle anlaşlabilecektir. Bu da kutsal metinlere yönelik tatbik edilecek varoluşsal bir hermönetik yardımıyla gerçekleşmelidir. İslam ve mitoloji ilişkisi ise Hıristiyanlık tecrübesinden oldukça farklıdır. İslam'ın kutsal metni Kur'an' da yer alan ve mitlerle benzer bir anlatım diline sahip "kıssa" adı verilen anlatılarda, aktarılan olayın "hak" olduğuna ilişkin kesin bir vurgunun yapılması Kur'an' da mitlere yer verilmediği kanaatini desteklemektedir. Ancak Kur'an' da mitlerin var olmadığına yönelik inanç esas alınsa bile İslam'dan hareketle teşekkül eden kültürlerin içinde mitlerin yer almadığı da söylenemez. Göcen tam da bu noktada Süleyman Çelebi tarafından Hz. Muhammed'in (sav) hayatını anlatmak üzere kaleme alınan mevlidin barındırdığı mitik öğelere ve etrafında gelişen ritüellere dikkat çekmekte, böylece İslam kültürü içerisinde mitik öğelerin ve anlatıların bir şekilde yer bulduğunu belirtmektedir (ss. 91-98).

Mitosu psikolojinin ilk biçimi olarak gören Karen Armstrong'un insanoğlunun daima mit yapıcı olduğunu belirtmesi Göcen'in mit üretmeyi psikolojik bir ihtiyaç ile açıklamasıyla örtüşür. Bu ihtiyaç insanlığın ilk dönemlerinden itibaren mitin ritüel, şiir, roman, resim, heykel, mimari, tiyatro ve sinema gibi araçlar vasitasıyla üretilmesini, aktarılmasını ve yeniden üretilmesini tetiklemiştir. Nitekim günümüzde sinemanın modern mitoloji olarak görülmesi, mitin hala üretildiğinin önemli işaretleri arasındadır. Dolayısıyla insanı anlamaya dönük çabaların sadece belli bir zaman ve mekân sınırına odaklanması yeterli olmayacaktır. Bu yetersizlik Carl G. Jung'u geçmişi yani mitleri bilmeye sevk etmiştir. Çünkü mitleri bilmek, insan davranışlarının kökenini bilmektir. Günümüzdeki birçok psikolojik rahatsızlığın mitik öğelerden hareketle isimlendirilmesi de insanoğlunun hala kadim zamana ait açıklamaları önemsediğini göstermektedir. Özellikle mitlerin psikolojinin önemli veri kaynaklarından biri kabul edilmesi "psikomitoloji" gibi yeni bir çalışma sahası da ortaya çıkarmıştır (ss. 106-108).

Göcen, mitin ne'liği, özellikleri ve tarihsel serencamı gibi başlıklar altında oldukça kapsayıcı ve derli toplu bir girişin akabinde mit-din ve mit-psikoloji ilişkilerini neredeyse bütün yönleriyle ilk bölümde ele almıştır. Yazar bu doyurucu incelemesini mit ve din arasındaki ilişkinin psikoloji tarihindeki ele alınış biçimleriyle sür- 
dürmektedir. Psikolojinin bir bilim olarak felsefeden ayrı ele alındığı ilk evre - ki Göcen'e göre bu evre aynı zamanda din psikolojisinin de başladığı zaman dilimidir - insan davranışına yansıdığı ölçüde dini dikkate almış ve çoğunlukla dini tecrübe ve mistisizm konu başlıklarını önemsemiştir. Buna rağmen din psikolojisinin kurucu babalarindan J. Wundt ve W. James gibi isimlerin incelemelerinde mite yer verdikleri bilinse de, özellikle dinler tarihçileri, parçacı yaklaşımlarından ötürü ilk dönem psikologlarının mitik öğeleri kullanarak ortaya çıardıkları verileri dini olguların anlaşılmasında yetersiz bulmuşlardır (s. 114)

Göcen'e göre ikinci evrede ise din-bilim çatışması merkezinde mitlerin kullanılması ve insanlık tarihindeki rolünün yeniden belirlenmesi gözlemlenmektedir. Dinin psikolojik kökenine yönelik incelemelerde dini bağımlı bir değişken olarak ele alan psikologların mitolojiye tam da bu noktada başvurdukları görülmüştür. Buna göre mitler insanın kutsal ile tecrübesinde Tanrı ve din düşüncesinden bağımsız olduğu varsayılan bir ortamın ürünü olarak öne çıkarılmıştır. Bu durum bir yandan mitler aracılığıyla dinin indirgemeci bir perspektiften ele alınmasına, öte yandan ise mitlerin yeniden gün yüzüne çıkmasına ve akademik incelemelerde etkin bir şekilde kullanılmasına sebep olmuştur. Tam da bu minval üzere Göcen, mit ve psikanalizin yolunun kesiştiğini düşünmektedir. İnsanın ve insanlığın çocukluk çağlarını mitsel zaman tasvirinde bir nevi aynılaştıran bu girişim, bir birey olarak insanın geçmişine yönelse de zamanla 'insanlı̆̆ın geçmişi'ni inceler olmuştur. Bu noktada Jung'un gayretini zikretmek gerekmektedir. Çünkü o çağdaşı Freud gibi mitosları, dinin "psikolojik ihtiyaçları gideren bir hikaye" olduğu tezini temellendirmek için kullanmak yerine, onları insanlıkla yaşıt bir gerçeklik olarak kabul etmiş̧tir. Jung'un mitin ve dinin sembolik dilini çözümleyerek insan psikolojisinin sembolik dili olan rüyaların anlamını keşfetmeye çalışması, Göcen'e göre mit, din ve psikoloji üçlüsünün insanı anlama çabasında birlikte değerlendirildiği en önemli adım olarak belirmektedir. Bu adım hümanist psikoloji ile daha da güçlenmiştir (s. 119)

Türkiye' de ise batıdaki gelişiminin aksine ilk dönem din psikologlarının mistisizm ve dini tecrübe gibi konular üzerine fazlaca eğilmediği, inançsızlık, din değiştirme ve metodoloji meselelerinin 
ise oldukça geç bir dönemde ele alındığı görülmektedir. Göcen özellikle din psikolojisi sahasında çalışan araştırmacıların mit ve mitoloji üzerine neredeyse değinmediklerini söylemektedir. Bu açıdan Göcen'in çalışmasının önemli bir eksiği gidereceği muhakkaktır (s. 122).

Kutsalın etkinliğinin insanlık tarihindeki azalan seyir çizgisi nedeniyle mitolojiden doğan boşluğun modern psikoloji ile doldurulduğu söylenebilir mi? Ya da psikoloji mitolojinin işlevini üstlenebilir mi? Göcen kitabının üçüncü bölümünde mitoloji-psikoloji karşılaşmasının analizini kişiler ve kuramlar üzerinden yapmaktadır (s. 126).

Modern psikolojinin kurucu babası olarak kabul edilen J. Wundt, bilincin karmaşık yapısını yalın öğeler halinde ele alarak bu öğeler arasındaki yasayı keşfetmeye odaklanan yapısalcı bir yöntemle psikolojiye yaklaşmıştır. Dini "milletler psikolojisi" olarak tanımlayan Wundt için mitoloji de bu psikolojinin kayıtlarıdır. Wundt'un bu yaklaşımı dinin en azından bireysel değil toplumsal bir ölçekte ele alınabileceğini göstermişse de dinin aşkın boyutunu ihmal etmesi nedeniyle eksitir (ss. 128-129). Modern insanı anlamak için kadim insanı ve insanlık tarihini bilmenin önemine vurgu yapan Freud için ise kadim insanın yaşamının temelinde içgüdüsel dürtülerin tatmini vardır. Freud'a göre kültür bu dürtülerin bastırılması neticesinde ortaya çıkarken, din de cinsel bastırmaların nevrotik bir ifadesi olarak tanımlanmıştır. Kadim insanın iç dünyasının sembolik bir dil bağıyla birlikte günümüze kadar aktarılmasını mitler sayesinde mümkün olduğunu düşünen Freud, psikolojiye dair pek çok tezini mitolojik öğeler kullanarak izah etmiştir. Örneğin Prometheus'un insanlığa ateşi hediye etmesinin bedeli olarak her gün ciğerinden bir parça koparılmasına rağmen ciğerinin yenilenmesi motifi, Freud'a göre insandaki libidinal arzuların yenilenmesi ve sürekliliğine işaret etmektedir. $\mathrm{O}$, erkek çocukların babaya olan kıskançlıkları ve anneye olan cinsel düşkünlüklerini Oedipus mitosuyla, kız çocuklardaki yoksunluğu ise babasının ölümünden sorumlu tuttuğu annesinin ölmesini isteyen Elektra mitosu ile açklamaya çalışır. Yine Freud eşcinsellik ile kendi bedenine aşık olan Narkissus mitosu arasında bir bağ kurar (ss. 136-142). Freud'un mitosları kadim insanı anlamak için incelemek yerine kendi teorilerini 
mitos ile desteklenmeye çalıştığına yönelik eleştirilere Göcen de katılmaktadır. Freud'un elinde mitoslar, deyim yerindeyse meşruiyet aracı olarak işlev görmektedir. Ya da Fromm'un da işaret ettiği üzere Freud, mitte var olanı anlamak yerine kendi teorisini mite söyletmeye çalışmaktadır. Çünkü mitos çemberi içindeki unsurlardan yalnızca kendi teorilerini destekleyenlere yönelik bir açıklamaya girişmektedir. Göcen'in de altını çizdiği üzere Freud'un bir yandan sadece hastalarındaki belirtilerden yola çıkması esasında inceleme sahasının sınırlılığını, öte yandan ise kullandığı mitosların sadece Yunan Mitolojisinene ait oluşu açıklama sahasının da oldukça dar olduğunu ve buradan üretilen sonuçların tüm insanlığa teşmil edilemeyeceğini göstermektedir (ss.152-163). Sonuç olarak mitosları yalnızca geriye dönük, parçacı ve hatta indirgemeci bir yaklaşımla ele alması, mitosların taraflı bir şekilde anlaşılmasına sebep olmaktadır. Yine de Freud, mitoloji-psikoloji karşılaşmasının önemli eşiklerinden birisi olarak kabul edilir.

Göcen, Freud incelemesinin akabinde Jung'un mitoslara yönelik yaklaşımına yer vermektedir. Jung'a göre mitoslar kolektif bilinçdışının tezahürleridir. Mitosları yalnızca cinsellik ölçeğinde ele almamasından ötürü Jung'un mit ve sembollerin derinliğini Freud'dan daha fazla kavradığı düşünülür. Yazar, Jung'un mitoloji anlayışını daha iyi izah edebilmek adına psişe ve arketip kavramlarının Jungçu kullanımına odaklanmıştır. Psişe, Jung'a göre hem bir varoluş hem de oluştur. İçinde bilinç, kişisel bilinçdışı ve kolektif bilinçdışı vardır. Bilinç, insanın farkında olduğu zihin yapısı, kişisel bilinçdışı ise bilince ulaşmamış ya da bilince ulaştıktan sonra bastırılmış dürtülerin biriktiği kişilik düzeyidir. Jung, kolektif bilinçdışını bireysel yaşam ve tecrübeyle oluşmayan, aksine bütün insanlıkta var olan ve nesillerce aktarılan arketip adındaki tasarımları içeren psişenin en derin katmanı olarak tanımlamaktadır. Arketip ise insan kültürünü oluşturan yapı taşları ve sürekli tekrarlanan davranış kalıplarıdır. Göcen bu tanımlar eşliğinde Jung'un özellikle "Ben, Persona, Gölge, Anima-Animus ve Tanrı" arketipleri üzerinde fazlaca durduğunu ifade etmektedir (ss. 177-182). Jung psikolojisinde mitlerle birlikte sürekli başvurulan bir diğer araç ise rüyalardır. Ona göre rüyalar kişileştirilmiş mitler, mitler de kişileştirilmiş rüyalar olarak tanımlanır. Rüyaların dilini çözmeyi insanı anlamakla özdeş gören Jung açısından rüyalardaki sembollerin karşılığını bilmek zorunludur. Tıpkı mitler gibi sembolik bir dile 
sahip olan rüyalar da Jung'a göre bilinçdışının bir ürünüdür; evrensel, estetik ve kolektiftir. Göcen'e göre Jung'un Freud'a nazaran mitoslar üzerinde daha titiz çalışması, mitoloji-psikoloji ilişkisinin seyri açısından önemli bir ilerleme olarak görülebilir. Ancak o da Freud gibi mitosları kendi psikolojik tezleri için kullanmaktan geri durmamıştır. Öte yandan kutsalın tezahürlerini aktaran mitosları yalnızca kolektif bilinçdışına itmekle de kutsalın aşkın boyutunu ihmal etmiştir (ss. 196-206).

Freud ve Jung'un mitolojiye ilişkin değerlendirmelerinin ardından Göcen, psikoloji ve hümanizm kavşağının en önemli isimlerinden Eric Fromm'a yer verir. Fromm, dini; insanın varoluş sorununa biçimsel ve özenle ayrıntılandırılmış bir yanıt olarak tanımlamakta, ancak dinden ziyade dini alana yönelik tutumlar üzerinden insanlığı ele almaktadır. "Sahip olmak" ve "olmak" fiillerini eksene alarak modern insanı "sahip olma" eğiliminden ötürü tüketici, kadim insan ise "olmak" fikri ekseninde bir hayat tercih ettiği için üretici olarak görmektedir. Günümüz insanı sahip olmak ile özgürleşeceğini düşünmekte, ancak sahip olma düzeyi arttıkça sahip olduğu nesnelerin esiri olmaktadır. Araçların amaçsallaştığı bir zamanın mahkumu olan modern insan yeni tanrıcıklar üretmekte, bu yönüyle ilkel kabile dinlerine benzer bir dindarlık modeli geliştirmektedir. Maddi sahiptelikten doğan mükemmelliği edinme tutkusuna karşın kadim insanlar için din, insanın kendisini mükemmelleştirmeye yönelik bir araçtır. Ona göre mitoslarda yer alan kahramanlar da "olmak" eğilimini tercih eden kimselerdir. Bu minval üzere Fromm mitosları da insanı anlama çabasının önemli verileri olarak görmektedir. Ayrıca mitoslar ve rüyalar arasındaki benzerlikleri keşfetmeye çalışan Fromm açısından her iki yapı da insana aittir. Rüyalar insan ruhunun, mitoslar ise insanlığın yaşanmışlığının izlerini taşımaktadır. Mitosları geçmiş zaman bilgeliklerinin sembol diliyle ifade edilmesi olarak gören Fromm, hayret etme iştahını yitirmesinden ötürü modern insanın sembollerin dilini keşfedemediği ve bu sebeple mitosları "akıldışı" kategorisine yerleştirerek onları gerçeklikten ve hayattan uzaklaştırdığını iddia etmektedir (ss. 224233).

Psikoloji ve mitoloji ilişkisinde Göcen'in yer verdiği bir diğer isim ise J. Campbell'dır. Mitolojileri hikaye, mitosları ise o hikayeyi oluşturan kelimeler olarak tanımlayan Campbell'a göre mitosların 
huşu duygusu uyandırma, kozmoloji yaratma, toplumsal düzeni tesis etme ve insan hayatının nasıl yaşanacağına ilişkin bir pedagoji ortaya koyma işlevleri vardır. Bu işlevler ancak mitoslar yaşamın bir gerçekliği olarak algılandığında anlamlı hale gelmektedir. Kahramanlık mitoslarının anlaşılmasına monomit kavramıla yeni bir soluk getiren Campbell, kahramanın serüvenini "yola çıııs, yücelme ve dönüş" perdeleriyle standardize etmiştir. Göcen'e göre, kahramanlık mitosu her ne kadar arketipik erkek kahramanın dişsal yolculuğunu sembolize etse de, gerçekte kahramanın içsel yolculuğunu anlatmaktadır. Esasında bu kendi hikayesinin baş aktörü olan her birey için geçerli bir kurgudur. İnsan hayatının önemli geçişleri Campbell'ın monomit evrelerine benzer şekilde ölüm ve yeniden doğum sarmalını tekrar eder; bu geçiş evresinde birey adeta kahramanın serüvenine paralel olarak mitle özdeşleşir ve ritler aracılığıyla yeni bir başlangıcın perdesini aralar (ss. 235-244).

Göcen, kitabının son bölümünü ise din psikolojisi-mitoloji ilişkisine ayırmaktadır. Amacı din ve psikoloji bağlamında ortaya çıkan olguları objektif bir şekilde incelemek olan din psikolojisi, insanı bütüncül olarak değerlendirebilmek için din, inanç ve maneviyata dair önemli veriler sunan mitoslarla ilgilenmek durumundadır. Yazara göre mitosların hem psikolojik hem de dini bir yöne sahip olması bu ilgiyi zorunlu hale getirmektedir (ss. 245-247).

Mitosu kutsalın hikayesi olarak tanımlamak aynı zamanda onu sadece tanrısallığa ait bir hikaye olarak kabul etmek değildir. Göcen de bu hususa Armstrong'un "mitler sadece tanrıların değil, aslında insanların kendi hikayesidir" ifadesiyle dikkat çekmektedir. Bu durumun en bariz örneği mitoslardaki tanrı tasavvurlarıdır. Bilhassa politeist geleneklerdeki "üstün güç" bağlamındaki tanrı tasavvurlarının antropomorfik (insan biçimli) ya da zoomorfik (hayvan biçimli) olarak tasvir edilmesi, insanın güce dair tasavvurlarını da yansıtmaktadır. Burada "kutsal olan", insan gerçekliğinde bütünüyle kavranıl(a)maz olduğu için nesneleştirilmekte, bu nesneleştirme faaliyeti ise mitosların sembolik dili aracılığıyla gerçekleştirilmektedir. Yazar bu sürecin tersinin de kimi kutsal kişilerin (kral, kraliçe, büyücü vs.) üstün güçlere sahip olarak betimlenmesiyle mitoslarda görüldüğünün altını çizmektedir. Hıristiyanlık'ın tanrısallığı İsa Mesih enkarnasyonunda tarihselleştirmesi ve insanoğlu İsa'y1 tanrıoğlu formunda ilahlaştırması yukarıdaki tasavvur sürecinin 
çift yönlülüğünü anlatması bakımından oldukça önemlidir (s. 252263).

Göcen'e göre din psikolojisi-mitoloji ilişkisinin izini sürmek için ilk olarak Tanrı tasavvurlarının nasıl ortaya çıktığına ilişkin birbirinden farklı teorilere bakmak gerekmektedir. Freud bu tasavvurların ilişkiselliğine dikkat çekerek çevresel faktörlerin yönlendirici etkisini öne çıkarmakta, Piaget ise insanın bilişsel gelişimine paralel olarak tanrı tasavvurunun değişmekte ve olgunlaşmakta olduğunu iddia etmektedir. Öte yandan Jung ise bu durumu teslis üzerinden açıklamaya çalışmaktadır. $\mathrm{O}$, insanın çocukluk, gençlik ve yetişkinlik/olgunluk dönemlerine karşılık olarak sırasıyla baba, oğul ve kutsal ruh şeklinde tanrı tasavvurlarına sahip olduğunu belirtmektedir. Fromm ise tanrı tasavvurlarını daha çok dişilik-erillik ikiliği üzerinden ele almakta ve toplumsal dönüşümlerin doğal olarak tanrı tasavvurlarını etkilediği savunmaktadır. Göcen, Fromm'un söz konusu teorisini Armstrong'un avcı toplayıcı toplumlarda baskın olarak görülen eril tanrı figürünün neolitik devrimde edilgenleştiği ve yerini tanrıça figürlerine bıraktığını öne süren görüşü ile açıklamaktadır. Tanrıların dişil ve eril tasavvurlarını izaha yönelik ortaya atılan pek çok iddiaya da yer veren yazarın çoğu din psikologlarını mezkur konuya dair İslam'ın görüşlerini ihmal etmekle eleştirmesi son derece yerindedir. Bu noktada ülkemizde yapılan çalışmalardan da bahseden Göcen, çocukluk döneminde anlatılan hikâyeler vasıtasıyla edinilen tanrı tasavvurunun yetişkinlikte daha çok Allah'ın sıfatları üzerinden şekillendiğini öne süren çalışmaları zikretmekte$\operatorname{dir}$ (ss. 258-266).

Göcen'e göre din psikolojisi-mitolojisi ilişkisinin belirgin bir şekilde görüldügü diğer bir zemin ise insanın anlam arayışıdır. Bu arayışın kodlarını çözmek ve yaşadığı dünyayı anlamlandırabilmek için insanoğlu mitoslara - özellikle köken ve yaratılış mitoslarına başvurmaktadır. Görünürde yaşadığımız evrenin ve içindekilerin kökenine ya da nasıl oluştuğuna dair veriler sunan kozmoloji mitosları, esasında insanoğluna evrenin fiziksel teşekkülünü ve doğal yasalarını tıpkı günümüzde bilimin yaptığı bir açıklama ile izah etme iddiasında değildir. $\mathrm{O}$ insana bütüncül bir resim sunarak kendisini o resme göre konumlandırmasını telkin etme işlevine sahiptir. Göcen'e göre mitosların kazandırdığı bu anlam, aynı zamanda din, psikoloji ve mitolojinin de ortak zeminidir (ss. 268-279). 
Göcen mitos ile kutsal arasındaki ilişkiyi ise "mit maneviyat ihtiyacını karşılar mı?" başlı̆̆ı altında ele almaktadır. Yazar, mitos ve kutsal arasındaki ilişkiyi bilmenin esasında kutsala ilişkin yanlış değerlendirmelerden kaynaklı kötücül algıyı ya da kutsalı kuşatma iddiasındaki popüler yapıları, ayrıca kutsalı yaşama tecrübesinin insanlığa sağladığı katkıyı bilmek demek olduğunun altını çizer. Bu bağlamda mitoslar ölüme ve eskatolojiye ilişkin anlatılarla bir yandan öleceğini bilen bir varlık olan insana bu kaçınılmaz sonla nasıl başa çıkacağını öğretirken, diğer yandan ise hayat trajedisinin sonrasındaki belirsizliğe ışık tutmaktadır (s. 295).

Son bölüm içinde mitos ve ritüel arasındaki ilişkiye ayrıca değinen Göcen, pek çok araştırmacıya ait ritüel tanımlarından hareketle mitos ve ritüelin kaçınılmaz birliğinin altını çizmektedir. Biri olmadan diğerini bütünüyle anlamak mümkün değildir. Mitoslar ritüeller vasıtasıyla yinelenir, o anda yaşanır ve aktarılırlar. İkisini kaybetmemek adına tabular oluşturulmuştur. Müzik, kurban ve dans öğeleri ritüellere eşlik ederek katılımcılar arasındaki uyumu düzenler ve böylece yaşanılan zamanın kırılması ve mitsel zamanla bütünleşme hedeflenir. Bu bütünleşme yeryüzünde kutsal olarak kabul edilen bir mekan üzerinden yine kutsal addedilen bir zaman dilimi içinde gerçekleşmelidir. Doğal olan veya insan eliyle inşa edilen bu kutsal mekanlar evreni sembolize etmekte ve bir merkez düşüncesi kurmaktadır. Bu düşünceden ilham alan mimari yapılar da yine kutsalla bütünleşmeyi sağlayacak bir formda kurgulanmaktadir (ss. 305-318).

Çalışmasında mitosların modern dönemde yeniden üretilmesi meselesine de yer veren Göcen, söz konusu üretimin orijinal değil esasında var olan mitosların kimi kırıntılarının birleştirilmesinin ürünü olduğuna işaret etmektedir. Modern dönem mitoslardan dolayısıyla kutsaldan - bağımsız bir kültür inşa etmek istemektedir. Ancak tüketim davranışlarını yönlendirebilmek ve süreklilik kazandırabilmek için mitik imgelerle örülü bir medya dili de oluşturulduğu kolaylıkla fark edilmektedir. Yine kadim zamanda sağlık problemleri yaşayan insanların kendilerine kozmogoni mitosları anlatılmak suretiyle iyileştirilmelerine benzer bir şekilde günümüzde de "bibliyoterapi" olarak bilinen 'hikaye anlatarak' tedavi/terapi etme yönteminin kullanılması, mitosların-hikayelerin 
sadece tarihin belli dönemine ait malzemeler olmadığını ortaya koymaktadır. Göcen'e göre mitoslar hala güncelliğini koruyan işte bu psiko-sosyal işlevlerinden ötürü sadece bazı disiplinlerin değil aynı zamanda din psikolojisinin de doğrudan alanına girmektedir (ss. 323-347).

İnsanı mitosu üretmesi bakımından özne, ondan etkilenmesi bakımından ise nesne olarak gören Göcen, kitap süresince mitosu kadim zamanla bağlantılı olarak ele almakla birlikte, onun insanlık tarihi boyunca var olan ve varlığını devam ettirecek olan bir kültür gerçekliği olduğu iddiasını kitabın bütününde işlemektedir. Yazar açısından insan her ne kadar yaşadığı zaman ve mekanın çocuğu olsa da ilk insan ile son insan arasındaki yapısal süreklilik, insanı anlamak açısından dikkate alınmak zorundadır. İşte bu sebeple din psikolojisi açısından mitosları bilmek, kadim insanın dini davranış kalıplarını keşfederek insana dair bütüncül bir anlama ulaşmaya yönelik önemli bir adım olarak görülür. Bu gayeden ötürü mitosların gerçek mi yoksa gerçek-dışı hikayeler mi olduğu sorusunu ihmal ederek onların işlevlerine odaklanan Göcen, mitosları bir ayna gibi kendi yaşadığımız çağa tutarak kendimizi ve kurduğumuz dünyayı hem anlayabileceğimizi hem de anlamlandırabileceğimizi göstermeye çalışmaktadır. Mitolojiyi akademik bir araştırma sahası olarak seçenler için bir başvuru kitabı olma özelliği taşıyan Göcen'in bu eseri, özellikle Din Psikoloji alanındaki araştırmacılar açısından ileride müstakil birer çalışma olarak ele alınacak başlıklara yer vermesi açısından da kanaatimizce literatürde önemli bir yere sahip olacaktir.

Bilal PATACI

Arş. Gör., İstanbul Üniversitesi, İlahiyat Fakültesi, Dinler Tarihi Anabilim Dalı. 